\section{(2) OPEN ACCESS}

\title{
Biallelic GINS2 variant p.(Arg114Leu) causes Meier- Gorlin syndrome with craniosynostosis
}

\author{
Maria J Nabais Sá 이, ${ }^{1,2}$ Kerry A Miller, ${ }^{3}$ Mary McQuaid, ${ }_{1}^{4}$ Nils Koelling, ${ }^{3}$ \\ Andrew 0 M Wilkie (1) ${ }^{3}$ Hugo Wurtele, ${ }^{4}$ Arjan P M de Brouwer, ${ }^{1}$ Jorge Oliveira (1) 5,6
}

\begin{abstract}
- Additional supplemental material is published online only. To view, please visit the journal online (http://dx doi.org/10.1136/jmedgenet2020-107572)
\end{abstract}

For numbered affiliations see end of article.

\section{Correspondence to}

Dr Maria J Nabais Sá

Department of Human Genetics (route 836), Radboud University Medical Center, P.O. box 9101 , 6500 HB, Nijmegen, The Netherlands;

maria.nabaissa@gmail.com

MJNS and KAM contributed equally.

Received 5 November 2020 Accepted 14 July 2021
Check for updates

(C) Author(s) (or their employer(s)) 2021. Re-use permitted under CC BY. Published by BMJ.

To cite: Nabais Sá MJ, Miller KA, McQuaid M, et al. $J$ Med Genet Epub ahead of print: [please include Day Month Year]. doi:10.1136/ jmedgenet-2020-107572

\begin{abstract}
Introduction Replication of the nuclear genome is an essential step for cell division. Pathogenic variants in genes coding for highly conserved components of the DNA replication machinery cause Meier-Gorlin syndrome (MGORS).
\end{abstract}

Objective Identification of novel genes associated with MGORS.

Methods Exome sequencing was performed to investigate the genotype of an individual presenting with prenatal and postnatal growth restriction, a craniofacial gestalt of MGORS and coronal craniosynostosis. The analysis of the candidate variants employed bioinformatic tools, in silico structural protein analysis and modelling in budding yeast.

Results A novel homozygous missense variant NM_016095.2:c.341G>T, p.(Arg114Leu), in GINS2 was identified. Both non-consanguineous healthy parents carried this variant. Bioinformatic analysis supports its classification as pathogenic. Functional analyses using yeast showed that this variant increases sensitivity to nicotinamide, a compound that interferes with DNA replication processes. The phylogenetically highly conserved residue p.Arg114 localises at the docking site of CDC45 and MCM5 at GINS2. Moreover, the missense change possibly disrupts the effective interaction between the GINS complex and CDC45, which is necessary for the CMG helicase complex (Cdc45/MCM2$7 /$ GINS) to accurately operate. Interestingly, our patient's phenotype is strikingly similar to the phenotype of patients with CDC45-related MGORS, particularly those with craniosynostosis, mild short stature and patellar hypoplasia.

Conclusion GINS2 is a new disease-associated gene, expanding the genetic aetiology of MGORS.

\section{INTRODUCTION}

Meier-Gorlin syndrome (MGORS) is characterised by a triad of clinical findings consisting of: (1) prenatal and postnatal growth retardation, (2) microtia, and (3) absent or hypoplastic patellae. ${ }^{1}$ This disorder is caused by pathogenic variants in genes coding for evolutionarily conserved components of the replication machinery of the nuclear genome-ORC1, ORC4, ORC6, CDT1, CDC6, GMNN, CDC45, MCM5 and DONSON..$^{2-7}$ Six ORC proteins (ORC1-6), Cdc6, Cdt1 and a heterohexamer of MCM proteins (MCM2-7) form a prereplication complex, which is activated by binding of Cdc45 and the heterotetramer GINS (GINS1-4) to MCM2-7. ${ }^{8}$ The resultant preinitiation CMG complex (Cdc45/MCM2-7/GINS) is a DNA helicase that separates the two strands of the DNA double helix at replication origins, subsequently enabling their replication. ${ }^{8}$

The genotype of individuals with MGORS requires at least one allele of genes encoding essential DNA replication factors allowing for some residual activity (hypomorphic variant). ${ }^{2-6}$ Furthermore, less severe phenotypes are often associated with two hypomorphic variants, while more severe phenotypes result from a combination of a hypomorphic and a loss-of-function variant. ${ }^{1}$ Nevertheless, in approximately $20 \%$ of individuals no pathogenic variants have been detected. ${ }^{1}$ Here, we describe the first patient with a homozygous disease-causing variant in GINS2, a subunit of the preinitiation CMG helicase, presenting with craniosynostosis and fulfilling the clinical diagnosis of MGORS

\section{METHODS}

The family was enrolled with informed consent into the Genetics Basis of Craniofacial Malformations study. The individual's phenotype was longitudinally and systematically evaluated. Exome capture, sequencing and analysis of DNA extracted from peripheral blood cells of the proband and both parents were carried out as described in online supplemental methods. We analysed the data assuming complete penetrance, allowing for the possibility of either a de novo variant (dominant) or biallelic inheritance (recessive). In silico protein analysis of CMG structures was performed for mutation prediction over stability and interactions, as detailed in online supplemental methods. One patient variant was further characterised using budding yeast Saccharomyces cerevisiae, as described in online supplemental methods, online supplemental table 5, online supplemental table 6 .

\section{RESULTS}

A 2-month-old girl was referred for genetic evaluation due to intrauterine growth restriction (IUGR), short stature, microcephaly and facial dysmorphisms. She was the only child of a nonconsanguineous healthy Portuguese couple with an unremarkable family history. During pregnancy, IUGR was diagnosed at the 29th week of gestation. Fetal structural abnormalities, infections and teratogens were excluded. She was born at $37^{+5}$ gestational weeks, by eutocic delivery with Apgar scores 9 and 10, at first and fifth minutes. At birth, her 


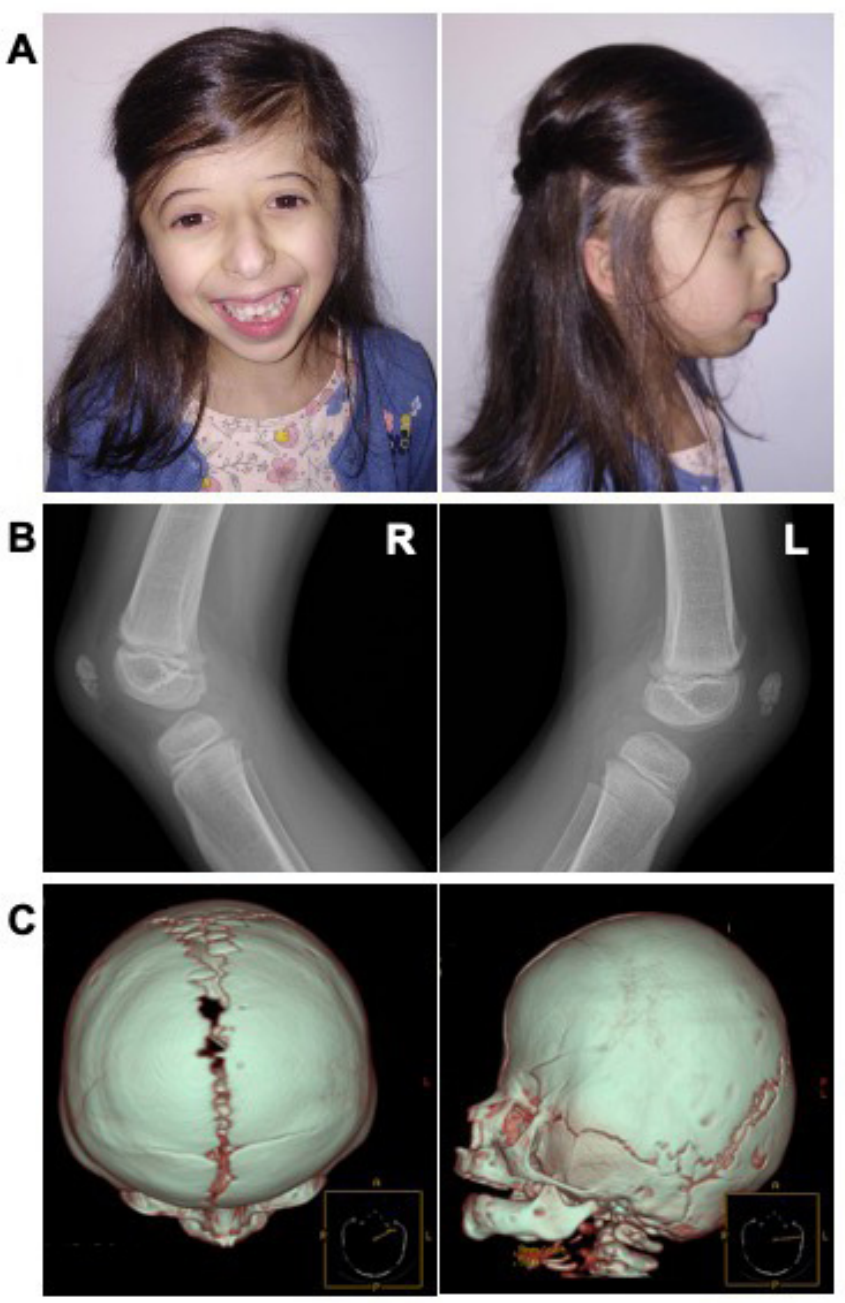

Figure 1 Clinical findings of an individual with a homozygous missense GINS2 variant. (A) Craniofacial features of Meier-Gorlin syndrome at 6 years of age, including microtia, thin eyebrows, a narrow nose with a convex nasal ridge, microstomia, full lips and microretrognathia. (B) Lateral radiographic view of both knees at 7 years of age, showing hypoplastic patellae. (C) 3D reconstruction of cranial CT scans at 5 months old, demonstrating an incomplete premature fusion of coronal sutures. L, left knee; $R$, right knee.

weight was $2260 \mathrm{~g}$ (1st centile; -2.2 SD), her length was 47 $\mathrm{cm}(\sim 10$ th centile) and her head circumference (HC) was 30.5 $\mathrm{cm}(<1$ st centile; $-3 \mathrm{SD})$. She had neonatal jaundice and mild hypotonia. Poor suction and feeding difficulties were noticed and gastro-oesophageal reflux was diagnosed. Newborn metabolic screening was normal. Newborn hearing screening failed, but auditory-evoked potentials at age of 10 days were within the normal electrophysiological limits.

She presented with craniofacial dysmorphic features, which evolved with age (figure 1). Her head was microcephalic and brachycephalic and her neck was short. At 6 months, her face was round with a narrow forehead and a low hairline, mid-face hypoplasia and microretrognathia. Ears were small, low set and posteriorly rotated with an atretic external auditory canal. Eyes were prominent and palpebral fissures were downslanted. Her nose was short with a wide, depressed nasal bridge, a convex nasal ridge, hypoplastic nares, low insertion of the columella and long philtrum. Her mouth was small with downturned corners, full lips and a high narrowed palate. She also had short and tapering fingers, short toes, a sacral dimple, an anteriorly placed anus and hypopigmented macules on the abdomen and upper back. At 6 years of age, hypopigmented macules were also observed on the arms and legs.

A bilateral coronal craniosynostosis was confirmed by cranial CT performed at 5 months old (figure 1), and surgically corrected at 17 months. Delayed teeth eruption was observed, with the first tooth erupting after 16 months of age. Her height, weight and HC improved with age (online supplemental table 1). Psychomotor development was adequate. During childhood, she had recurrent respiratory infections.

Extensive system-based investigation was performed. Left ureteropelvic ectasia was noticed during an abdominal and renovesical ultrasound at 16 days. During the cardiological examination at 1 month of age, a patent foramen ovale and an atrial septal defect (ASD) of $5 \mathrm{~mm}$ with a left-right shunt were diagnosed. At 15 months, no ECG abnormalities were observed. Surgical closure of the ASD took place at 5 years and 9 months old. Four months before this surgery, she had an ostium secundum-type ASD of about $10 \mathrm{~mm}$ and a sinus venous-type ASD of about 5 $\mathrm{mm}$, resulting in a left-right shunt and dilated right cavities. A mild tricuspid regurgitation with a right ventricle/right auricle gradient of about $16 \mathrm{~mm} \mathrm{Hg}$ had also been detected. A complete skeletal X-ray at 21 months did not show skeletal abnormalities. Left wrist X-ray at 22 months demonstrated delayed bone age (10-12 months). Ophthalmological evaluation at 22 months diagnosed myopia. Lymphocyte immunophenotyping study at 2 years and 10 months did not show quantitative changes suggestive of any immunodeficiency. Finally, knee radiography, performed at 7 years of age, showed hypoplastic patellae (figure 1).

Given prenatal and postnatal growth delay, bilateral coronal craniosynostosis, cardiac defects and craniofacial dysmorphic features, standard diagnostic genetic investigation was performed. Karyotype, chromosomal microarray and direct sequencing of the FGFR2, FGFR3 (exons 7 and 10) and TWIST did not identify pathogenic variants. Through exome sequencing, a homozygous missense variant NM 016095.2:c.341G > T, p.(Arg114Leu), was identified in the GINS2 gene (MIM*610609) as the most likely candidate genetic cause of the observed primordial dwarfism and craniosynostosis phenotype. Other variants in candidate genes (online supplemental table 2) were excluded from further experimental studies. The single heterozygous variant in UBQLN3 gene was reported in gnomAD at a low frequency (two heterozygotes listed in this database). As for the compound heterozygous variants identified in four different genes, they were also underrated considering: (1) the lower deleterious score or inconsistency between bioinformatic predictors (ANKRD11, RIF1 and SYNJ2); and (2) the protein's known biological function did not correlate with the patient's phenotype (AHNAK). The cumulative size of all runs of homozygosity ( $\mathrm{ROH}$ ) was estimated at 18.6 $\mathrm{Mb}$, representing $<1 \%$ of the genome and excluding any close consanguineous relationship between the parents. The inspection of $\mathrm{ROH}$ showed that the GINS2 candidate variant was located in the patient's largest $\mathrm{ROH}(2.04 \mathrm{Mb})$ detected through exome sequencing data; only four other smaller ROHs (varying between 1.17 and $1.66 \mathrm{Mb}$ ) were detected. Populational data $\left(\right.$ gnom $\mathrm{AD}^{9}$ ) demonstrated that this variant has an extremely low frequency $(0.020 \%$; $7 / 34498$ in the 'Latino' population), which can be extrapolated using the Hardy-Weinberg equilibrium to a frequency of homozygotes of about $1 / 9.72 \times 10^{7}$. Interestingly, the presence of homozygous variants in GINS2 is extremely rare in gnom $\mathrm{AD}^{9}$ : so far, only two missense (and no loss-of-function) homozygous variants have been listed. Of note, this is a small gene with an open reading frame of $555 \mathrm{bp}$. 
A

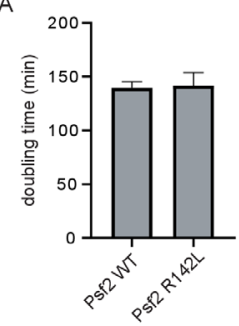

C

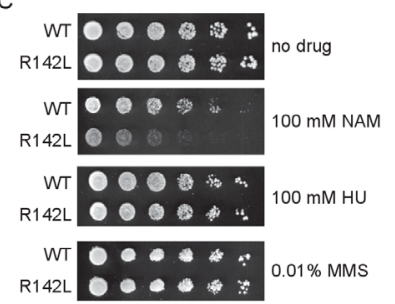

B

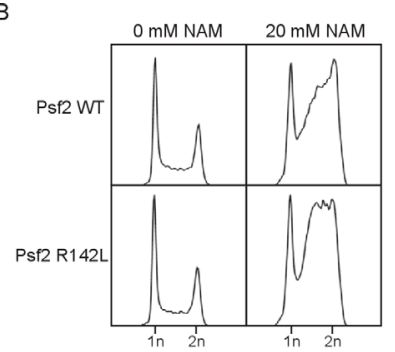

$\mathrm{D}$

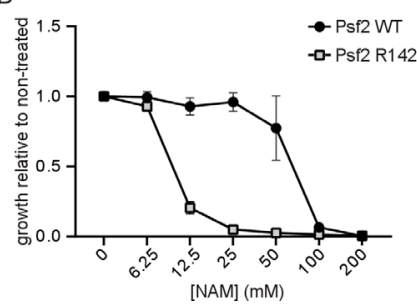

Figure 2 Strains of yeast expressing Psf2-R142L show reduced growth and altered cell cycle progression in the presence of nicotinamide (NAM). (A) $O D_{630}$ of yeast cultures was monitored for 48 hours and doubling time was derived from exponential regression of the resulting growth curve $(n=3)$. (B) Cell cycle profiles of actively replicating yeast cultures were assessed by flow cytometry after 8 hours of growth in the presence or absence of $20 \mathrm{mM}$ NAM. (C) Serial fivefold dilutions of yeast were grown on solid media in the presence or absence of $100 \mathrm{mM}$ NAM, $100 \mathrm{mM}$ hydroxyurea (HU) or $0.01 \%$ methyl methanesulfonate (MMS) at $30^{\circ} \mathrm{C}$ for 72 hours $(n=3)$. (D) Yeasts were cultured for 48 hours in the presence of a range of concentrations of NAM. Growth in the presence of NAM is presented as a fraction of growth in the absence of NAM $(n=3)$. WT, wild type.

Finally, the substitution of the highly conserved arginine (down to yeast, considering 11 species; online supplemental figure 1) by a leucine, corresponding to a moderate physicochemical difference (Grantham dist: $102(0-215))$, is classified by bioinformatic analysis as likely pathogenic (PolyPhen-2, SIFT, MutationTaster). The Combined Annotation Dependent Depletion (CADD) score was 28.3. ${ }^{10}$

Protein structural analysis shows that this missense variant affects one residue (p.Arg114) located in an alpha helix domain and in close proximity to CDC45, MCM5 and GINS3 polypeptides (online supplemental figure 2A). Given the availability of its three-dimensional structure, both from humans and $S$. cerevisiae, we analysed the variant's impact on protein interaction and stability. In different protein structures (or conformations) from S. cerevisiae, the corresponding residue-p.Arg142-establishes several hydrogen bonds with other neighbouring amino acids from Psf2 (GINS2) itself but also with Cdc45 (one conserved residue in both species) and $\mathrm{Mcm} 5$ (an isofunctionally substituted residue) (online supplemental figure $2 \mathrm{~B}-\mathrm{D}$ ). Structure prediction by comparative modelling of protein three-dimensional structures suggested that the arginine to leucine substitution disrupts all of these interactions (online supplemental figure $2 \mathrm{E}-\mathrm{G}$ ).

To evaluate the functional impact of the GINS2 p.(Arg114Leu) substitution, S. cerevisiae strains expressing Psf2 p.(Arg142Leu) (Psf2-R142L) were generated. No obvious differences in cell doubling time or cell cycle distribution were observed between strains expressing wild-type Psf2 (Psf2-WT) and those expressing Psf2-R142L on unperturbed growth (figure 2A,B). However, testing the effects of a series of compounds that induce DNA replication stress revealed that nicotinamide (NAM), a compound that causes DNA damage through inhibition of

histone deacetylases of the sirtuin family, impaired the growth of Psf2-R142L-expressing cells (figure 2C,D). NAM-induced inhibition of the sirtuins Hst 3 and Hst 4 causes DNA damage in yeast. Moreover, hst $3 \Delta$ hst $4 \Delta$ double mutation causes synthetic lethality when combined with epitope-tagged versions of DNA replication factors, indicating that subtle defects in DNA replication protein function can be detected using elevated NAM sensitivity as a read-out. While exposure to NAM resulted in the accumulation of cells in late $S$ and $\mathrm{G} 2$ phases of the cell cycle for both Psf2-WT and Psf2-R142L-expressing cells (figure 2B), Psf2-R142L-expressing cells accumulated earlier in S phase than those expressing Psf2-WT, indicative of impaired DNA replication. Together, these observations indicate that the GINS2 p.(Arg113Leu) substitution negatively impacts the function of the corresponding protein.

So far, no other patient with GINS2-related MGORS has been identified, specifically using GeneMatcher or by contacting experts in this syndrome (see the Acknowledgements section for further details), corroborating the rarity of MGORS caused by pathogenic GINS2 variants.

\section{DISCUSSION}

We describe a patient with growth delay, craniofacial dysmorphisms and craniosynostosis, and in whom a homozygous missense variant in the GINS2 gene was identified. Although it is classified as of unknown clinical significance using the guidelines proposed by the American College of Medical Genetics and Genomics (ACMG), several lines of evidence support that this variant in GINS2 is an additional cause of MGORS.

First, the homozygous p.(Arg114Leu) variant in GINS2 is likely deleterious. This variant was identified in both healthy parents in heterozygosity. Since they are not consanguineous, they may share a very distant common ancestor, which is consistent with the homozygosity data. The high degree of intolerance of GINS2 to homozygous variants (even of missense type) is suggestive of high selective pressure, thus supporting the possibility of GINS2 being a disease-causing gene. Additionally, the in silico analysis also supported the pathogenicity of the p.(Arg114Leu) substitution, which occurred in a highly conserved residue in GINS2. Finally, modelling of the p.(Arg114Leu) substitution in the budding yeast $S$. cerevisiae showed that in yeast this substitution does not affect growth either under normal conditions or in the presence of hydroxyurea or methyl methanesulfonate, but confers sensitivity to DNA replication stress caused by the histone deacetylase inhibitor NAM, consistent with partially defective functions of Psf2 (yeast GINS2).

Second, this novel GINS2 variant was identified in an individual with clinical features reminiscent of MGORS (online supplemental tables 3 and 4). She has the cardinal features of this syndrome, such as prenatal and postnatal growth restriction, patellar hypoplasia, microtia and coronal craniosynostosis. Additionally, she has overlapping skeletal, cardiac, gastrointestinal and anal abnormalities, and normal intelligence.

Third, the functional interactions of GINS2 and its role in DNA replication strengthen its causality in MGORS. GINS2 (OMIM*610609; GINS complex subunit 2) is part of the tetrameric GINS complex-composed of GINS1/GINS2/GINS3/ GINS4-which is conserved in eukaryotes, from $S$. cerevisiae to Homo sapiens. ${ }^{11-13}$ This complex was shown to play an essential role in the initiation of DNA replication and progression of DNA replication forks, ${ }^{11}{ }^{12}$ unwinding DNA for polymerase epsilon and binding preferentially to single-stranded DNA in the replicative helicase complex. ${ }^{14}$ The GINS tetramer interacts 
with CDC45 and MCM proteins to form the CMG helicase. The p.(Arg114Leu) substitution is located at the docking site of MCM5 and CDC45 at GINS2, which involves its N-terminal B-domain and its helical domain. ${ }^{15}$ The analysis of protein structural data suggested that this novel variant might compromise the interaction between GINS2 and both CDC45 and MCM5. Considering these subtle changes, we anticipated that the p.(Arg114Leu) missense variant might be hypomorphic, thus maintaining the partial function of GINS2. This is supported by the analysis of the equivalent Psf2-R142L substitution in yeast, which exhibited normal growth in several experimental conditions but a specific defect when exposed to NAM (figure 2).

Indeed, deletion of Psf1 in mice (GINS1 in humans) results in early embryonic lethality. ${ }^{12}$ Of note, Psf1 is largely expressed in active stem cell systems in mice, including adult bone marrow, thymus, testis and ovary, but not the remaining adult tissues. ${ }^{12}$ Interestingly, five patients with compound heterozygous variants in GINS1 were reported with neutropenia, natural killer cell deficiency and growth delay. ${ }^{16}$ Missense variants and variants located in the $5^{\prime}$ untranslated region resulted in lower GINS1 levels in patients' cells, which showed impaired GINS complex assembly, basal replication stress, impaired checkpoint signalling, defective cell cycle control and genomic instability, which could be rescued by wild-type GINS1. ${ }^{16}$ Although our patient did not present immunodeficiency, growth retardation was evident, in particular in utero and during early infancy.

Our patient's phenotype is strikingly similar to the phenotype of individuals with CDC45 variants, particularly those who presented with craniosynostosis and mild MGORS features. Interestingly, pathogenic homozygous or compound heterozygous variants in the CDC45 gene result in the distinctive MGORS clinical triad and frequently in craniosynostosis (OMIM\#617063; MGORS7). ${ }^{5}$ Noteworthy, our patient had both patellae, though hypoplastic, and short stature was mild. Additionally, she developed cardiac and anal abnormalities. Also, pathogenic variants in MCM5 and MCM4, other genes of the CMG helicase complex, were respectively associated with MGORS $^{6}$ and a distinct growth delay phenotype. ${ }^{17-20}$ Based on the functional interaction between the CMG complex and DNA polymerases, we propose that changes in this complex would affect DNA replication as a possible pathophysiological mechanism for GINS2-related MGORS. In line with this assumption, biallelic hypomorphic missense variants in GINS3 have been reported just recently, as an additional molecular cause of MGORS, suggesting defects in GINS genes as a cause of this clinical entity (Kannu et al, personal communication, 2020).

In summary, we report an individual with a homozygous likely disease-causing variant in GINS2 and with clinical features overlapping those of MGORS, including prenatal and postnatal growth delay, hypoplastic patellae and typical craniofacial dysmorphisms, such as microtia and craniosynostosis. The recognition of the GINS2 gene as a novel causative gene of MGORS is crucial for the anticipatory multidisciplinary care of affected individuals, as well as for genetic counselling, enabling parents the possibility of prenatal or preimplantation diagnosis. The apparent rarity of GINS2 variants associated with MGORS may be explained because the phenotype arises only in a narrow window of disturbed GINS2 function, intermediate between lethal and normal outcomes.

\section{Author affiliations}

'Department of Human Genetics, Radboud University Medical Center and Donders Institute for Brain, Cognition and Behaviour, Nijmegen, The Netherlands
${ }^{2}$ Unit for Multidisciplinary Research in Biomedicine, Instituto de Ciências Biomédicas Abel Salazar, Universidade do Porto, Porto, Portugal

${ }^{3}$ Clinical Genetics Group, MRC Weatherall Institute of Molecular Medicine, University of Oxford, Oxford, UK

${ }^{4}$ Maisonneuve-Rosemont Hospital Research Center, Montréal, Québec, Canada ${ }^{5}$ Centre for Predictive and Preventive Genetics (CGPP), Institute for Molecular and Cell Biology (IBMC), Universidade do Porto, Porto, Portugal

${ }^{6}$ UnIGENe, i3S - Instituto de Investigação e Inovação em Saúde, Universidade do Porto, Porto, Portugal

Acknowledgements The authors are very thankful to the proband and her family for their collaboration, which was fundamental for publishing this work. The authors would like to acknowledge the collaboration of Sonja de Munnik (Radboudumc, Nijmegen, The Netherlands), Ernie Bongers (Radboudumc, Nijmegen, The Netherlands) and Louise Bicknell (University of Otago, Dunedin, New Zealand), who informed the authors of the absence of individuals with biallelic GINS2 variants in their Meier-Gorlin cohorts.

Contributors MJNS collected the patient data and summarised the clinical and genetic findings. KAM, NK and AOMW performed and analysed the exome sequencing. JO participated in the bioinformatic data interpretation. HW and MM designed, performed and interpreted all functional assays. MJNS drafted the manuscript and APMdB, AOMW, MM, HW and JO participated in final draft revisions. All coauthors critically reviewed the manuscript and approved the final submitted version.

Funding Core facilities were supported by the WIMM Strategic Alliance (G0902418 and MC_UU_12025). This work was supported by the National Institute for Health Research (NIHR) Oxford Biomedical Research Centre Programme (AOMW), a Wellcome Senior Investigator Award 102731 (AOMW) and the Canadian Institute for Health Research PJT 159683 (HW).

Competing interests None declared.

Patient consent for publication Parental/guardian consent obtained.

Ethics approval The Genetics Basis of Craniofacial Malformations study was approved by the London-Riverside Research Ethics Committee, UK (reference 09/ H0706/20). The study was conducted in accordance with the Declaration of Helsinki Ethical Principles.

Provenance and peer review Not commissioned; externally peer reviewed.

Supplemental material This content has been supplied by the author(s). It has not been vetted by BMJ Publishing Group Limited (BMJ) and may not have been peer-reviewed. Any opinions or recommendations discussed are solely those of the author(s) and are not endorsed by BMJ. BMJ disclaims all liability and responsibility arising from any reliance placed on the content. Where the content includes any translated material, BMJ does not warrant the accuracy and reliability of the translations (including but not limited to local regulations, clinical guidelines, terminology, drug names and drug dosages), and is not responsible for any error and/or omissions arising from translation and adaptation or otherwise.

Open access This is an open access article distributed in accordance with the Creative Commons Attribution 4.0 Unported (CC BY 4.0) license, which permits others to copy, redistribute, remix, transform and build upon this work for any purpose, provided the original work is properly cited, a link to the licence is given, and indication of whether changes were made. See: https://creativecommons.org/ licenses/by/4.0/.

\section{ORCID iDs}

Maria J Nabais Sá http://orcid.org/0000-0002-9472-6050

Andrew O M Wilkie http://orcid.org/0000-0002-2972-5481

Jorge Oliveira http://orcid.org/0000-0003-3924-6385

\section{REFERENCES}

1 de Munnik SA, Bicknell LS, Aftimos S, Al-Aama JY, van Bever Y, Bober MB, ClaytonSmith J, Edrees AY, Feingold M, Fryer A, van Hagen JM, Hennekam RC, Jansweijer MCE, Johnson D, Kant SG, Opitz JM, Ramadevi AR, Reardon W, Ross A, Sarda P, Schrander-Stumpel CTRM, Schoots J, Temple IK, Terhal PA, Toutain A, Wise CA, Wright M, Skidmore DL, Samuels ME, Hoefsloot LH, Knoers NVAM, Brunner HG, Jackson AP, Bongers EMHF. Meier-Gorlin syndrome genotype-phenotype studies: 35 individuals with pre-replication complex gene mutations and 10 without molecular diagnosis. Eur J Hum Genet 2012;20:598-606.

2 Bicknell LS, Walker S, Klingseisen A, Stiff T, Leitch A, Kerzendorfer C, Martin C-A, Yeyati P, Al Sanna N, Bober M, Johnson D, Wise C, Jackson AP, O'Driscoll M, Jeggo PA. Mutations in $O R C 1$, encoding the largest subunit of the origin recognition complex, cause microcephalic primordial dwarfism resembling Meier-Gorlin syndrome. Nat Genet 2011:43:350-5.

3 Bicknell LS, Bongers EMHF, Leitch A, Brown S, Schoots J, Harley ME, Aftimos S, Al-Aama JY, Bober M, Brown PAJ, van Bokhoven H, Dean J, Edrees AY, Feingold M, 
Fryer A, Hoefsloot LH, Kau N, Knoers NVAM, Mackenzie J, Opitz JM, Sarda P, Ross A, Temple IK, Toutain A, Wise CA, Wright M, Jackson AP. Mutations in the pre-replication complex cause Meier-Gorlin syndrome. Nat Genet 2011;43:356-9.

4 Guernsey DL, Matsuoka M, Jiang H, Evans S, Macgillivray C, Nightingale M, Perry S, Ferguson M, LeBlanc M, Paquette J, Patry L, Rideout AL, Thomas A, Orr A, McMaster CR, Michaud JL, Deal C, Langlois S, Superneau DW, Parkash S, Ludman M, Skidmore DL, Samuels ME. Mutations in origin recognition complex gene Orc4 cause MeierGorlin syndrome. Nat Genet 2011;43:360-4.

5 Fenwick AL, Kliszczak M, Cooper F, Murray J, Sanchez-Pulido L, Twigg SRF, Goriely A, McGowan SJ, Miller KA, Taylor IB, Logan C, Bozdogan S, Danda S, Dixon J, Elsayed SM, Elsobky E, Gardham A, Hoffer MJV, Koopmans M, McDonald-McGinn DM, Santen GWE, Savarirayan R, de Silva D, Vanakker O, Wall SA, Wilson LC, Yuregir 00, Zackai EH, Ponting CP, Jackson AP, Wilkie AOM, Niedzwiedz W, Bicknell LS, WGS500 Consortium. Mutations in CDC45, Encoding an Essential Component of the Preinitiation Complex, Cause Meier-Gorlin Syndrome and Craniosynostosis. Am J Hum Genet 2016;99:125-38.

6 Vetro A, Savasta S, Russo Raucci A, Cerqua C, Sartori G, Limongelli I, Forlino A, Maruelli S, Perucca P, Vergani D, Mazzini G, Mattevi A, Stivala LA, Salviati L, Zuffardi O. MCM5: a new actor in the link between DNA replication and Meier-Gorlin syndrome. Eur J Hum Genet 2017;25:646-50.

7 Knapp KM, Sullivan R, Murray J, Gimenez G, Arn P, D'Souza P, Gezdirici A, Wilson WG Jackson AP, Ferreira C, Bicknell LS. Linked-read genome sequencing identifies biallelic pathogenic variants in DONSON as a novel cause of Meier-Gorlin syndrome. J Med Genet 2020;57:195-202.

8 Fragkos M, Ganier O, Coulombe P, Méchali M. DNA replication origin activation in space and time. Nat Rev Mol Cell Biol 2015;16:360-74.

9 Karczewski KJ, Francioli LC, Tiao G, Cummings BB, Alfoldi J, Wang Q, Collins RL, Laricchia KM, Ganna A, Birnbaum DP, Gauthier LD, Brand H, Solomonson M, Watts NA, Rhodes D, Singer-Berk M, England EM, Seaby EG, Kosmicki JA, Walters RK, Tashman K, Farjoun Y, Banks E, Poterba T, Wang A, Seed C, Whiffin N, Chong JX, Samocha KE, Pierce-Hoffman E, Zappala Z, O'Donnell-Luria AH, Minikel EV, Weisburd B, Lek M, Ware JS, Vittal C, Armean IM, Bergelson L, Cibulskis K, Connolly KM, Covarrubias M, Donnelly S, Ferriera S, Gabriel S, Gentry J, Gupta N, Jeandet T, Kaplan D, Llanwarne C, Munshi R, Novod S, Petrillo N, Roazen D, Ruano-Rubio V, Saltzman A, Schleicher M, Soto J, Tibbetts K, Tolonen C, Wade G, Talkowski ME, Genome Aggregation Database Consortium. Neale BM, Daly MJ, MacArthur dG. The mutational constraint spectrum quantified from variation in 141,456 humans. Nature 2020;581:434-43.
10 Rentzsch P, Witten D, Cooper GM, Shendure J, Kircher M. CADD: predicting the deleteriousness of variants throughout the human genome. Nucleic Acids Res 2019;47:D886-94.

11 Takayama Y, Kamimura Y, Okawa M, Muramatsu S, Sugino A, Araki H. Gins, a novel multiprotein complex required for chromosomal DNA replication in budding yeast. Genes Dev 2003:17:1153-65.

12 Ueno M, Itoh M, Kong L, Sugihara K, Asano M, Takakura N. Psf1 is essential for early embryogenesis in mice. Mol Cell Biol 2005;25:10528-32.

13 Aparicio T, Guillou E, Coloma J, Montoya G, Méndez J. The human GINS complex associates with Cdc45 and MCM and is essential for DNA replication. Nucleic Acids Res 2009;37:2087-95.

$14 \mathrm{Li} \mathrm{H}, \mathrm{O}^{\prime}$ Donnell ME. The eukaryotic CMG helicase at the replication fork: emerging architecture reveals an unexpected mechanism. Bioessays 2018;40.

15 Simon AC, Sannino V, Costanzo V, Pellegrini L. Structure of human Cdc45 and implications for CMG helicase function. Nat Commun 2016;7:11638.

16 Cottineau J, Kottemann MC, Lach FP, Kang Y-H, Vély F, Deenick EK, Lazarov T, Gineau L, Wang Y, Farina A, Chansel M, Lorenzo L, Piperoglou C, Ma CS, Nitschke P, Belkadi A, Itan Y, Boisson B, Jabot-Hanin F, Picard C, Bustamante J, Eidenschenk C, Boucherit S, Aladjidi N, Lacombe D, Barat P, Qasim W, Hurst JA, Pollard AJ, Uhlig HH, Fieschi C, Michon J, Bermudez VP, Abel L, de Villartay J-P, Geissmann F, Tangye SG, Hurwitz J, Vivier E, Casanova J-L, Smogorzewska A, Jouanguy E. Inherited GINS1 deficiency underlies growth retardation along with neutropenia and NK cell deficiency. J Clin Invest 2017;127:1991-2006.

17 Eidenschenk C, Dunne J, Jouanguy E, Fourlinnie C, Gineau L, Bacq D, McMahon C, Smith O, Casanova J-L, Abel L, Feighery C. A novel primary immunodeficiency with specific natural-killer cell deficiency maps to the centromeric region of chromosome 8 . Am J Hum Genet 2006;78:721-7.

18 Gineau L, Cognet C, Kara N, Lach FP, Dunne J, Veturi U, Picard C, Trouillet C, Eidenschenk C, Aoufouchi S, Alcaïs A, Smith O, Geissmann F, Feighery C, Abel L, Smogorzewska A, Stillman B, Vivier E, Casanova J-L, Jouanguy E. Partial MCM4 deficiency in patients with growth retardation, adrenal insufficiency, and natural killer cell deficiency. J Clin Invest 2012;122:821-32.

19 Hughes CR, Guasti L, Meimaridou E, Chuang C-H, Schimenti JC, King PJ, Costigan C, Clark AJL, Metherell LA. MCM4 mutation causes adrenal failure, short stature, and natural killer cell deficiency in humans. J Clin Invest 2012;122:814-20.

20 Casey JP, Nobbs M, McGettigan P, Lynch S, Ennis S. Recessive mutations in MCM4/ PRKDC cause a novel syndrome involving a primary immunodeficiency and a disorder of DNA repair. J Med Genet 2012;49:242-5. 